Alfarama Journal of Basic \& Applied Sciences

Faculty of Science Port Said University https://ajbas.journals.ekb.eg

ajbas@sci.psu.edu.eg

http://sci.psu.edu.eg/en/

January 2021, Volume 2, Issue 1

DOI: $\underline{10.21608 / a j b a s .2020 .42617 .1034}$

Submitted: 20-09-2020

Accepted: 11-10-2020

Pages: 16-27

\title{
Administration of Adipose Derived Mesenchymal Stem Cells Promotes Amelioration of Renal Function in Cisplatin-induced Acute Kidney Injury in Rats.
}

\author{
Ibrahem Mohey Eldeen ${ }^{1}$, Faten Zahran Mohamed ${ }^{2}$, Nashwa Mohamed Barakat ${ }^{3}$, Mohsen \\ Mohamed Mohamed Khedr ${ }^{4 \text {,* }}$ \\ ${ }^{1}$ Department of Chemistry, Faculty of Science, Port said university, Port said, Egypt. \\ ${ }^{2}$ Department of Chemistry, Faculty of Science, Zagazig University, Zagazig, Egypt. \\ ${ }^{3}$ Urology and Nephrology center, Mansoura University, Mansoura, Egypt. \\ ${ }^{4}$ Department of Chemistry, Faculty of Science, Port Said University, Port said, Egypt. \\ * Corresponding author: mohsenkhedr_74@yahoo.com.
}

\begin{abstract}
Cisplatin is a chemotherapeutic agent, causes nephrotoxicity when it was administered for long periods. Our study conducted an investigation into the effect of ADMSCs in attenuation of cisplatin induced AKI. A total of 90 Sprague-Dawley rats (180-220 g) were apportioned to three groups: control group, cisplatin group, and ADMSCs + CP group. Ten rats were sacrificed on the days 3, 7 and 11, the kidney tissues and blood samples were obtained. Renal functions, oxidative stress parameters, molecular studies and histopathological studies were analyzed, as well as ADMSCs isolation and characterization was done.

Cisplatin injection caused disturbance in kidney function through increasing serum creatinine, blood urea nitrogen and MDA, and decreasing GSH activity. The amelioration in renal function appeared at day 3 with the use of ADMSCs. Injection of cisplatin induced tubular apoptosis and inflammation by increasing Caspase-3 and $\mathrm{NF}_{\mathrm{KB}}$, in addition to tubular degenerations evaluated by pathological score, in contrast, ADMSCs group showed a significantly lowered inflammation and apoptosis at days 3, 7, 11. This study concluded that ADMSCs have reno-protective effects that can be explained by three possible mechanisms of action, targeting oxidative stress, targeting apoptosis and reducing inflammation through which it could improve cisplatin toxicity.
\end{abstract}

\section{Keywords:}

Cisplatin, nephrotoxicity, Adipose derived Stem cells.

\section{INTRODUCTION}

Acute kidney injury (AKI) is a clinical syndrome with high morbidity and mortality rates, as well as, renal excretory function rapidly decline causing accumulation of nitrogenous containing compounds (urea and creatinine) in blood. [1]. AKI can be caused by many types of conditions, from which drugs, that cause AKI in approximately $20 \%$ of patients, especially in seriously ill patients [2]. Acute kidney injury has a 
relatively common side effect, which can be seen in nearly $30 \%$ of patients after a single dose of CIS. It is thought that cisplatin-induced nephrotoxicity is a complex process that involving inflammation, oxidative stress, apoptosis, mitochondrial dysfunction and DNA damage [3].

Cisplatin (CIS) is a widely used for chemotherapeutic drug against a variety of tumors [4]. However, cisplatin was found to cause toxicity for many organs, particularly nephrotoxicity that results due to cumulation of cisplatin in renal tubules following its prolonged intake, causing limitation in its therapeutic use [5].

Depending on the different mechanisms, diverse renoprotective strategies have been developed. Stem cellbased therapy is one of the most growing therapeutic applications for organ repair [6], they are a promising tool for the treatment of damaged tissues, for instance connective tissue damage, neural and vascular disorders [7]. Several studies confirmed that stem cells and their different types can be used in the treatment of AKI in rat's models, most of these studies interested in bone marrow-derived MSCs (BM-MSCs) [8].

Mesenchymal stem cells can be segregated from a diversity of tissues, the most appropriate MSC source is the adipose tissue, due to its sampling risk for individual donors is lower than that of bone marrow, it needs an easier method for isolation, their harvested source could provide greater number of stem cells than BMSCs in which the aspiration process is highly invasive procedure and harvests only low numbers of cells [9].

Adipose derived mesenchymal stem cells (ADMSCs) have other several properties such as immunomodulatory effects, secretion of several growth factors and cytokines in addition to anti-apoptotic, anti-inflammatory and anti-oxidant activities, which enable them to be a promising tool in regenerative medicine application [10]. Hence, our study discussed the effects of ADMSCs on cisplatin induced acute kidney injury in rats as well as its underlying mechanism.

\section{MATERIALS AND METHODS}

\subsection{Animals}

Ninety male Sprague-Dawley (SD) rats, weighting (180-220) g. were housed in the animal research facility of Urology and Nephrology Centre, Mansoura University, Mansoura, Egypt, at a temperature of 20 ${ }^{\circ} \mathrm{C}$, humidity $55 \%$, with 12:12-h daylight/darkness, and allowed free access to food and water ad libitum. All animal experiments were given in accordance with the guidance of the care and use of laboratory animals and were complying with the guidance of the Urology and Nephrology center, Mansoura University ethical committee (Code \# MDP.19.12.35.R1).

\subsection{Preparation of Adipose-Derived MSCs:}

ADMSCs were obtained from the paragonadal fat of rates, where rates were subjected to anesthesia, and then the paragonadal fat was obtained, it was minced thoroughly with scissors and blades and then it was put in phosphate-buffered saline (PBS; Sigma-Aldrich, USA), after that it was centrifuged for $10 \mathrm{~min}$ at 2000 r.p.m. The supernatant was aspirated and the minced tissue was incubated with collagenase I $(0.075 \%)$ (Sigma-Aldrich, USA), for 1 hour at $37{ }^{\circ} \mathrm{C}$ whilst shaking for complete digestion, after digestion, the sample was dilute 1:1 in DMEM and $10 \%$ fetal bovine serum (FBS) (GIBCO, Thermo, USA), and then it was centrifuged at 2000 r.p.m for 10 min, the supernatant was discarded and then the pellet was suspended again in PBS, after that it was transferred to tissue culture flask containing low glucose-DMEM containing $0.25 \%$ trypsin, finally it was incubated for 24 hours in a 5\% $\mathrm{CO} 2$ incubator, the medium was removed from the flasks, and was refreshed every three days till the confluence of cells reached $70 \%$, after the $3^{\text {rd }}$ passage cells become ready to use.

\subsection{The phenotypic analysis of ADMSCs.}

The phenotypic analysis was performed by flow cytometric analysis to characterize MSCs where, ADMSCs after passage 3 were detached by trypsinization, the trypsinization process was inactivated by adding basal medium, the mixture was centrifuged, the supernatant was discarded and resuspended of the pellet was occurred in $100 \mu \mathrm{l}$ PBS in a cytometry tube, $10 \mu 1$ of each antibody (CD44- PE (Phycoerythrin) 
and CD45-FITC (fluorescein isothiocyanate) (BD Biosciences)) was added, the cells and their respective antibody were placed in the dark for $15 \mathrm{~min}$ at room temperature, after that washing of labeled cells by PBS, followed by fixation in flow buffer was occurred, and then cells were analyzed by using Epics $\mathrm{XL}^{\mathrm{TM}}$ flowcytometry (Beckman Coulter, Brea, CA, USA).

\subsection{Identification and homing of ADMSCs:}

Before transplantation of ADMSCs, and when the cells reached $80-90 \%$ confluence in the $3^{\text {rd }}$ passage, cells were incubated for 2 days at $37^{\circ} \mathrm{C}$ and $5 \% \mathrm{CO} 2$ in DMEM supplemented with $10 \mu \mathrm{m} / 1 \mathrm{BrdU}$ (5-bromo-2 deoxyuridine) (Thermo scientific, USA), and then the cells were collected within 30 min and were suspended in normal saline before transplanting into the rats [11].

\subsection{Experimental design:}

Group I (control group) ( $\mathbf{n = 3 0}$ ): by using $1 \mathrm{ml}$ normal saline rates were injected (intraperitoneally). Group II (cisplatin 'CIS' injected group) (n=30): by using a single dose of cisplatin $(6 \mathrm{mg} / \mathrm{kg})$ rates were injected (IP). Group III (cisplatin and ADSCs-treated group) $(\mathbf{n}=\mathbf{3 0})$ : In this group rats were injected with $0.5 \mathrm{ml}$ of culture media containing $5 \times 10^{6}$ MSCs into the tail vein, after 24 hours from cisplatin injection. Before sacrificing of each group, urine samples have been collected randomly from metabolic cages. Ten rats were sacrificed after 3 days from cisplatin injection, ten rats were sacrificed after 7 days from cisplatin injection, and ten rats were sacrificed after 11 days after cisplatin injection, and then blood samples and kidney tissue were obtained.

\subsection{Biochemical measurement:}

The levels of Blood urea nitrogen (BUN) were estimated according to the instructions of urea kit (Diamond diagnostics company, Berthelot enzymatic colorimetric method, Hannover, Germany), while the levels of serum creatinine were estimated in accordance with the instructions of creatinine kit (Diamond diagnostics company, Jaffe, calorimetric - kinetic, Hannover, Germany), urine protein was done using the Architect c4000 system (Abbott Diagnostics, Wiesbaden, Germany). Malondialdehyde (MDA) [12] and reduced glutathione (GSH) contents [13] in kidney tissues were estimated by using a reagent kit provided by Biodiagnostic (Giza, Egypt).

\subsection{BrdU Immunofluorescence Assay:}

Kidney tissues were placed in pre-warmed $\left(37^{\circ} \mathrm{C}\right)$ cell culture medium, and then was cut into thin slices ( $5 \mathrm{~mm}$ thickness), after which the culture medium was aspirated and was replaced by a sufficient amount of BrdU labeling medium and was incubated at $37^{\circ} \mathrm{C}$ for $30 \mathrm{~min}$, the labeling medium was discarded, the slides were washed with PBS, and were left to dry, after that the slides were placed with the blocking solution for $40 \mathrm{~min}$ at $37^{\circ} \mathrm{C}$, after that the slides were washed. A working solution of anti-BrdU was added and the slides were incubated with the working solution for $30 \mathrm{~min}$ at $37^{\circ} \mathrm{C}$, the slides were washed with PBS for $15 \mathrm{~min}$, and then anti-IgG-FITC was added to the slides, incubation at room temperature for $1.5 \mathrm{~h}$, and then washing for $15 \mathrm{~min}$ was carried out, finally the slides were evaluated by using a fluorescence microscope.

\subsection{Real-time $P C R$ for $\mathrm{NF}_{\mathrm{KB}}$ and caspase- 3 genes:}

Extraction of total RNA from kidney tissue homogenate was done according to the instructions of RNeasy purification reagent kit (Qiagen, USA), followed by generation of cDNA from $5 \mu \mathrm{g}$ of total RNA by using higher capacity cDNA reverse transcription kit (Applied Biosystem, USA), after that, SYBER Green PCR Master Mix (Applied Biosystem, USA) was used to perform the Quantitative RT-PCR analysis that was performed by using an Applied Biosystem (Step One ${ }^{\mathrm{TM}}$, USA).

PCR reaction was 1 cycle for $2 \mathrm{~min}$ at $50{ }^{\circ} \mathrm{C}$ for amplification, and 40 cycles, each of them consisting of three steps, denaturation step for $15 \mathrm{~s}$ at $95{ }^{\circ} \mathrm{C}$, annealing step for $1 \mathrm{~min}$ at $60{ }^{\circ} \mathrm{C}$ and elongation step for 1 min at $72{ }^{\circ} \mathrm{C}$. The relative expressions of Caspase- 3 and NF-kB were calculated by using $2^{-\Delta \Delta \mathrm{CT}}$ method. All 
values were normalized to glyceraldehyde-3-phosphate dehydrogenase (GAPDH) genes, primer sequence of genes was demonstrated in the table below.

\section{Primer sequence of genes:}

\begin{tabular}{|l|l|c|}
\hline Gene & \multicolumn{1}{|c|}{ Sequence } & Accession no. \\
\hline Caspase-3 & $\begin{array}{l}\text { F:5-GGACCTGTGGACCTGAAAAA-3 } \\
\text { R:5-GCATGCCATATCATCGTCAG-3 }\end{array}$ & NM_012922.2 \\
\hline NF-kB & $\begin{array}{l}\text { F:5-GGACAGCACCACCTACGATG-3 } \\
\text { R:5-CTGGATCACTTCAATGGCCTC-3 }\end{array}$ & NM_001276711.1 \\
\hline GAPDH & $\begin{array}{l}\text { F:5-TATCGGACGCCTGGTTAC-3 } \\
\text { R:5-CTGTGCCGTTGAACTTGC-3 }\end{array}$ & NM_017008.4 \\
\hline
\end{tabular}

\subsection{Histopathological examination:}

The kidney tissue was fixed in $10 \%$ buffered formalin, and then the kidney tissue was dehydrated in ascending grades of serial diluted ethyl alcohol, and finally cleared in xylene, after that the kidney tissue was embedded in paraffin for $24 \mathrm{~h}$, by using a microtome (Leica RM 2155, England), the kidney tissue was prepared into slices of about $4 \mu \mathrm{m}$ thickness and stained with hematoxylin / eosin (H\&E) for microscopic examination by using bright field light microscope (Olympus CX51 light microscope, Tokyo, Japan), Pictures were obtained by a PC-driven digital camera (Olympus E-620), computer software (Cell*, Olympus Soft Imaging Solution $\mathrm{GmbH}$ ).

\subsection{Statistical Analysis:}

Data were expressed as mean \pm SD. Statistical differences were determined by using ANOVA oneway analysis of variance taken $\mathrm{p}<0.05$ as a confidence interval. The histopathological parameters scores were reported as median. Differences in median were performed by Mann-whitney U test. All statistical analysis was performed using SPSS version 20 (IBM Corp., Armonk, NY, USA).

\section{RESULTS}

\subsection{Isolation and Characterization of ADMSCs:}

ADMSCs in the third passage appeared as spindle-shaped (Figure 1). Using flow cytometric analysis, the cultured cells expressing CD44 positive rate was $96.1 \%$ and the negative rate of CD45 was $8.1 \%$, these results were in accordance with expression characteristics of surface antigen of ADMSCs (Figure 2).

\subsection{Immunofluorescence with BrdU Labeling:}

ADMSCs were stained with BrdU to detect homing into the injured kidney. Labeled cells were positioned to the kidney and scattered in the glomeruli (Figure 3). 


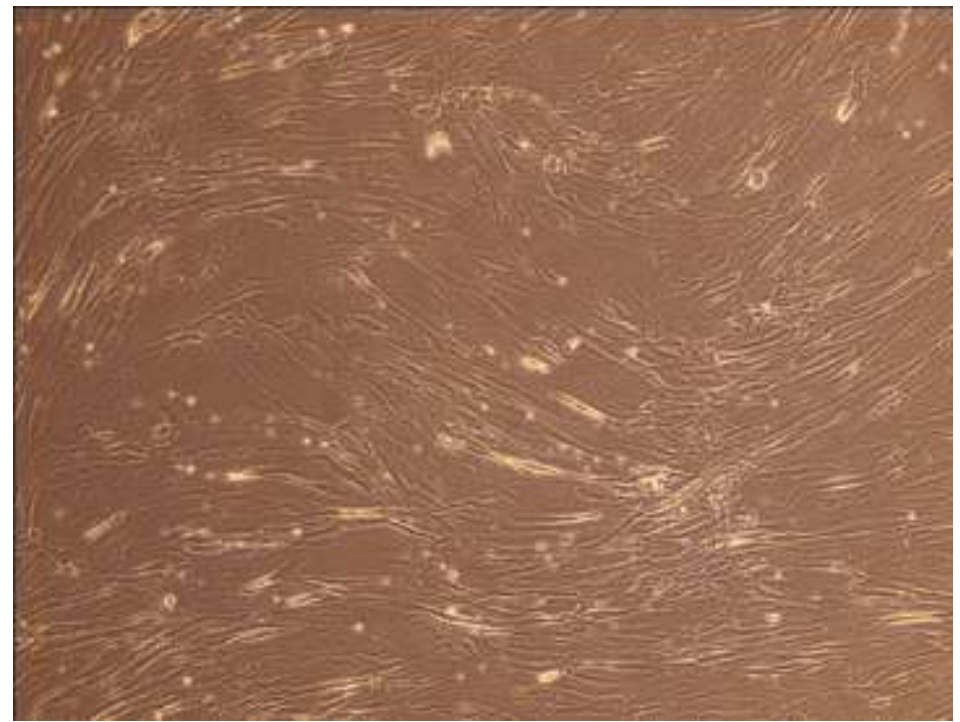

Fig. (1): Photomicrograph showing Adherent ADMSCs in the third passage (X40).
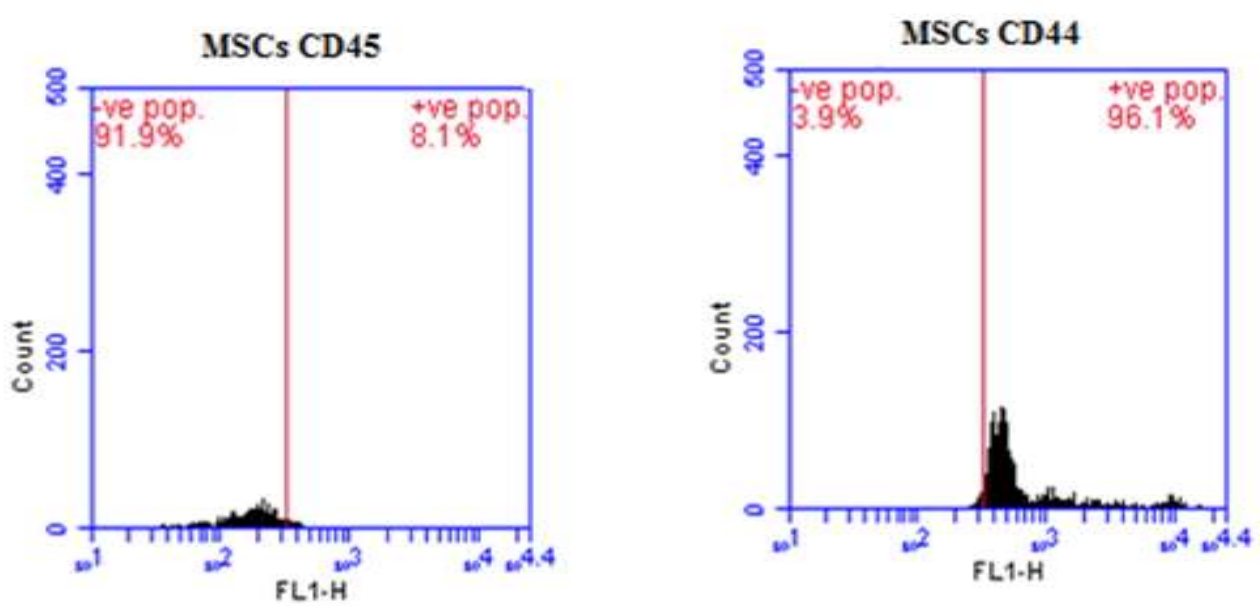

Fig. (2): Flow cytometry analysis of adipose derived mesenchymal stem cells showed that their expression of surface antigen CD45 was negative; but, their expression of surface antigen CD 44 was positive (at Passage 3).

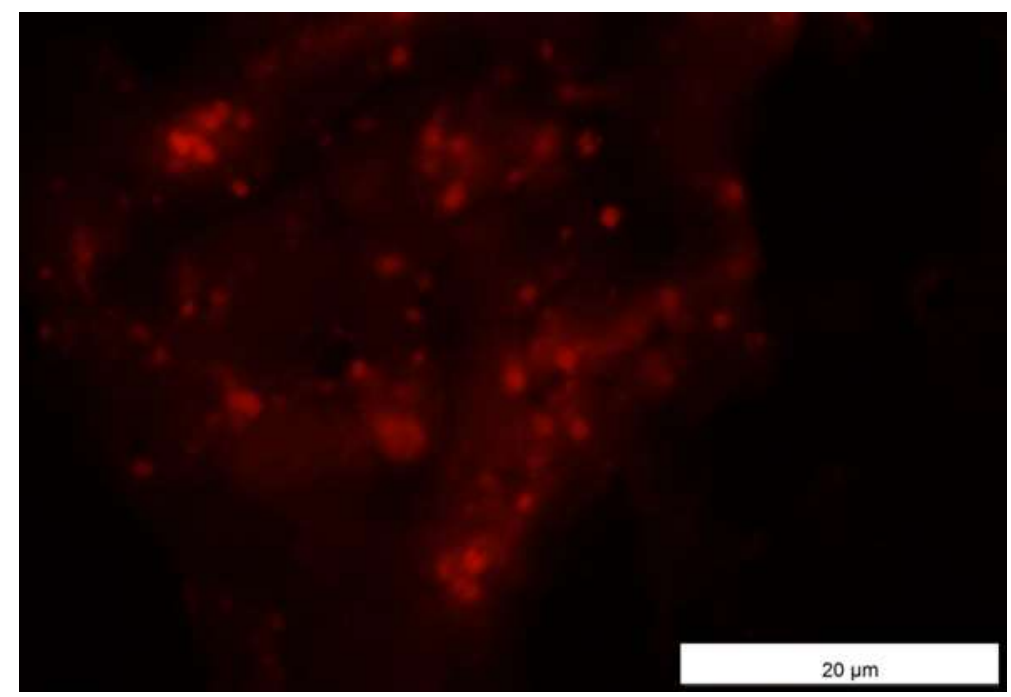

Fig. (3): Photomicrograph showing labeled ADMSCs with BrdU in kidney (X40). 


\subsection{Effects of ADMSCs on kidney dysfunction.}

Kidney function results (serum creatinine $(\mathrm{mg} / \mathrm{dl}), \mathrm{BUN}(\mathrm{mg} / \mathrm{dl})$ and urine protein $(\mathrm{mg} / \mathrm{dl})$ ), in all groups were shown in Table 1. Basal values of serum creatinine (SCr), blood urea nitrogen (BUN) and Urine Protein were compared among the three groups, the mean of serum creatinine, BUN and Urine Protein were significantly higher in the cisplatin group compared with the control group at 3,7 , and 11 days $(\mathrm{p}<$ 0.05), for the rats treated with ADMSCs the levels of BUN was significantly decreased compared with the non-treated group (cisplatin group). No significant difference was observed in BUN levels between ADMSCs group and the control group. Similarly, the serum creatinine level and urine protein level were significantly decreased in ADMSCs group compared with cisplatin group $(\mathrm{p}<0.05)$ and the results were similar to those of the normal group.

Table (1): Effect of ADMSCs on the levels of serum Creatinine, BUN and urine protein.

\begin{tabular}{|l|l|l|l|l|l|l|}
\hline Groups & \multicolumn{2}{|c|}{ 3D } & \multicolumn{2}{c|}{ 7D } & \multicolumn{2}{c|}{ 11D } \\
\hline SCr (mg/dI) & Basal & Test & Basal & Test & Basal & Test \\
\hline Control & $0.53 \pm 0.04$ & $0.56 \pm 0.05$ & $0.48 \pm 0.03$ & $0.56 \pm 0.06$ & $0.47 \pm 0.02$ & $0.55 \pm 0.06$ \\
\hline CIS & $0.43 \pm 0.12$ & $5.26 \pm 0.74^{\mathrm{a}}$ & $0.45 \pm 0.10$ & $3.55 \pm 0.43^{\mathrm{a}}$ & $0.41 \pm 0.11$ & $1.83 \pm 0.61^{\mathrm{a}}$ \\
\hline CIS + ADMSCs & $0.46 \pm 0.16$ & $2.73 \pm 0.57^{\mathrm{ab}}$ & $0.41 \pm 0.11$ & $1.76 \pm 0.36^{\mathrm{ab}}$ & $0.43 \pm 0.12$ & $1.13 \pm 0.22^{\mathrm{ab}}$ \\
\hline BUN (mg/dI) & & & & & & \\
\hline Control & $20.68 \pm 1.61$ & $21.23 \pm 1.31$ & $20.92 \pm 0.84$ & $22.16 \pm 0.72$ & $20.86 \pm 1.13$ & $22.85 \pm 1.26$ \\
\hline CIS & $21 \pm 2.28$ & $80.50 \pm 3.44^{\mathrm{a}}$ & $21.33 \pm 4.17$ & $53.5 \pm 5.44^{\mathrm{a}}$ & $21.5 \pm 1.87$ & $38.16 \pm 3.81^{\mathrm{a}}$ \\
\hline CIS +ADMSCs & $21 \pm 2.60$ & $54.33 \pm 4.88^{\mathrm{ab}}$ & $22.5 \pm 4.08$ & $35.66 \pm 3.77^{\mathrm{ab}}$ & $21.83 \pm 2.63$ & $28.50 \pm 3.44^{\mathrm{ab}}$ \\
\hline $\begin{array}{l}\text { Urine Protein } \\
\text { (mg/dl) }\end{array}$ & & & & & & \\
\hline Control & $1.03 \pm 0.12$ & $1.06 \pm 0.17$ & $1.06 \pm 0.15$ & $1.03 \pm 0.17$ & $1.05 . \pm 0.12$ & $0.99 \pm 0.12$ \\
\hline CIS & $1.17 \pm 0.41$ & $5.78 \pm 0.67^{\mathrm{a}}$ & $1.01 \pm 0.34$ & $4.59 \pm 0.64^{\mathrm{a}}$ & $0.92 \pm 0.14$ & $2.89 \pm 0.58^{\mathrm{a}}$ \\
\hline CIS + ADMSCs & $0.90 \pm 0.16$ & $3.73 \pm 0.36^{\mathrm{ab}}$ & $0.86 \pm 0.12$ & $2.51 \pm 0.78^{\mathrm{ab}}$ & $0.80 \pm 0.19$ & $1.65 \pm 0.46^{\mathrm{ab}}$ \\
\hline
\end{tabular}

Significant difference ( $\mathrm{p} \leq 0.05)$, versus ${ }^{a}$ control group, versus ${ }^{\mathrm{b}}$ cisplatin group by one-way analysis of variance (ANOVA) followed by posthoc multiple comparisons (Scheffé test).

\subsection{Effects of ADMSCs on oxidative stress markers.}

Tissue levels of MDA significantly increased in cisplatin group, while tissue levels of GSH significantly decreased in cisplatin group compared with control group and ADMSCs groups $(\mathrm{P}<0.05)$, which confirm the progress of AKI in cisplatin group, in contrast to cisplatin group, administration of ADMSCs resulted in optimizing of such changes in these parameters, which appeared through the significant decrease in the tissue level of MDA, and the significant increase in the tissue level of GSH compared with cisplatin group (Table 2). 
Table (2): Effect of ADMSCs on kidney Malondialdehyde (MDA) and glutathione (GSH) concentration and the expression level of Caspase- 3 and $\mathrm{NF}_{\mathrm{KB}}$ gene respectively.

\begin{tabular}{|c|c|c|c|}
\hline Groups & 3D & 7D & 11D \\
\hline \multicolumn{4}{|c|}{ MDA ( nmol / g. tissue) } \\
\hline Control & $12.4 \pm 0.5$ & $12.42 \pm 0.44$ & $12.39 \pm 0.6$ \\
\hline CIS & $54 \pm 2.1^{\mathrm{a}}$ & $50 \pm 2.2^{\mathrm{a}}$ & $44.2 \pm 3.09^{\mathrm{a}}$ \\
\hline $\mathrm{CIS}+\mathrm{SC}$ & $27.2 \pm 1.3^{\mathrm{ab}}$ & $23.2 \pm 2.3^{\mathrm{ab}}$ & $18.1 \pm 0.8^{\mathrm{ab}}$ \\
\hline \multicolumn{4}{|l|}{ GSH (mg / g. tissue) } \\
\hline Control & $6.08 \pm 0.08$ & $6.1 \pm 0.11$ & $6.4 \pm 0.2$ \\
\hline CIS & $1.5 \pm 0.1^{\mathrm{a}}$ & $1.61 \pm 0.16^{\mathrm{a}}$ & $1.7 \pm 0.06^{\mathrm{a}}$ \\
\hline $\mathrm{CIS}+\mathrm{SC}$ & $3.2 \pm 0.2^{\mathrm{ab}}$ & $3.8 \pm 0.17^{\mathrm{ab}}$ & $5.7 \pm 0.15^{\mathrm{ab}}$ \\
\hline \multicolumn{4}{|l|}{ Caspase-3 } \\
\hline Control & $0.96 \pm 0.07$ & $0.98 \pm 0.11$ & $0.96 \pm 0.2$ \\
\hline CIS & $6.85 \pm 0.17^{\mathrm{a}}$ & $6.41 \pm 0.06^{\mathrm{a}}$ & $6.04 \pm 0.17^{\mathrm{a}}$ \\
\hline $\mathrm{CIS}+\mathrm{SC}$ & $4.5 \pm 0.08^{\mathrm{ab}}$ & $4.04 \pm 0.13^{\mathrm{ab}}$ & $2.5 \pm 0.66^{\mathrm{ab}}$ \\
\hline \multicolumn{4}{|l|}{$\mathbf{N F}_{\mathbf{K B}}$} \\
\hline Control & $1.14 \pm 0.05$ & $1.17 \pm 0.08$ & $1.15 \pm 0.1$ \\
\hline CIS & $6.5 \pm 0.24^{\mathrm{a}}$ & $5.9 \pm 0.09^{\mathrm{a}}$ & $5.48 \pm 0.27^{\mathrm{a}}$ \\
\hline $\mathrm{CIS}+\mathrm{SC}$ & $3.7 \pm 0.15^{\mathbf{a b}}$ & $3.1 \pm 0.13^{\mathrm{ab}}$ & $1.73 \pm 0.05^{\mathrm{ab}}$ \\
\hline
\end{tabular}

significant difference $(\mathrm{p} \leq 0.05)$, versus ${ }^{\mathrm{a}}$ control group, versus ${ }^{\mathrm{b}}$ cisplatin group by one-way analysis of variance (ANOVA) followed by posthoc multiple comparisons (Scheffé test).

\subsection{Effects of ADMSCs on the expression level of $\mathrm{NF}_{\mathrm{KB}}$ and caspase- 3 in kidney tissues:}

The significant increase in the expression levels of the inflammatory marker $\mathrm{NF}_{\mathrm{KB}}$ and apoptotic marker caspase-3 in cisplatin group compared with control group $(\mathrm{p}<0.001)$, proved the progress of AKI in cisplatin group, on the contrary to cisplatin group, ADMSCs group showed significantly down regulation in the expression level of those genes as compared with cisplatin group $(\mathrm{p}<0.001)$ (Figure 4, 5). 


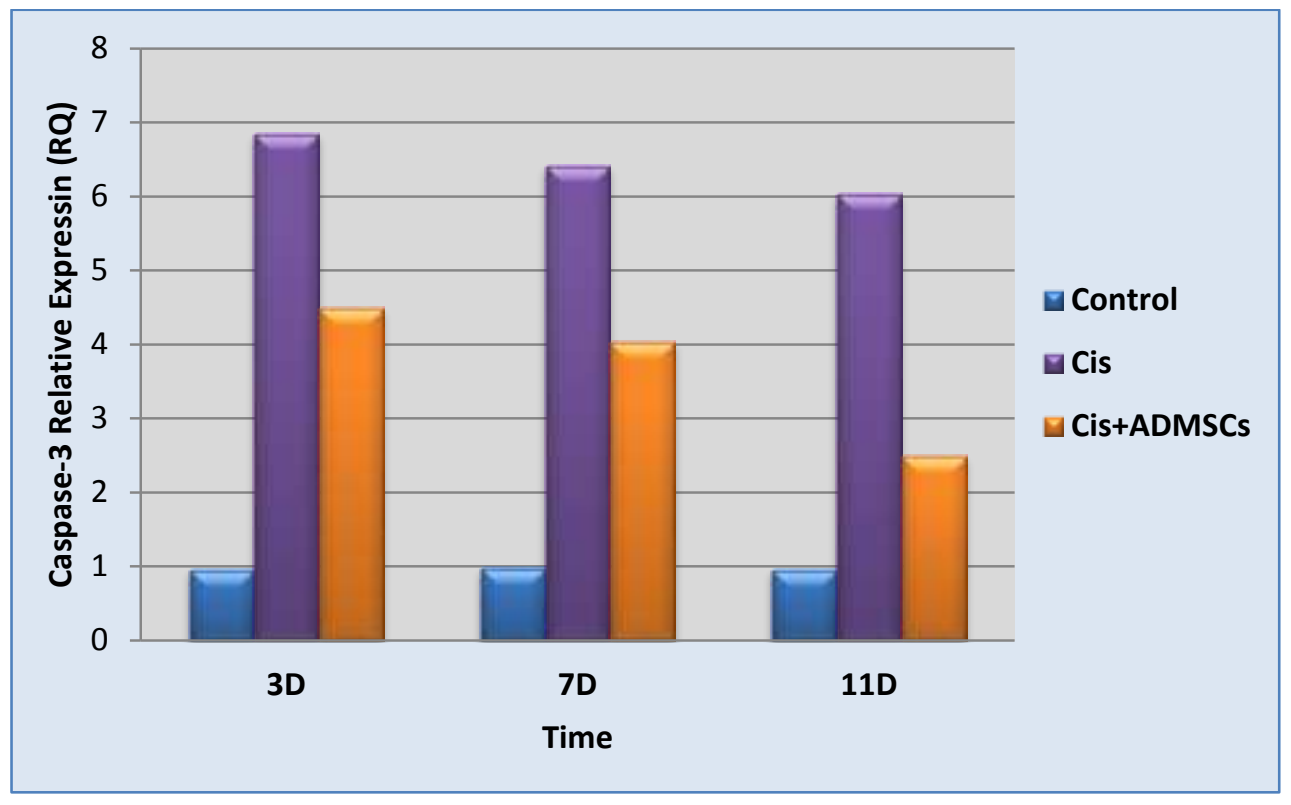

Fig. (4): Effect of ADMSCs on caspase-3 expression in kidney tissue.

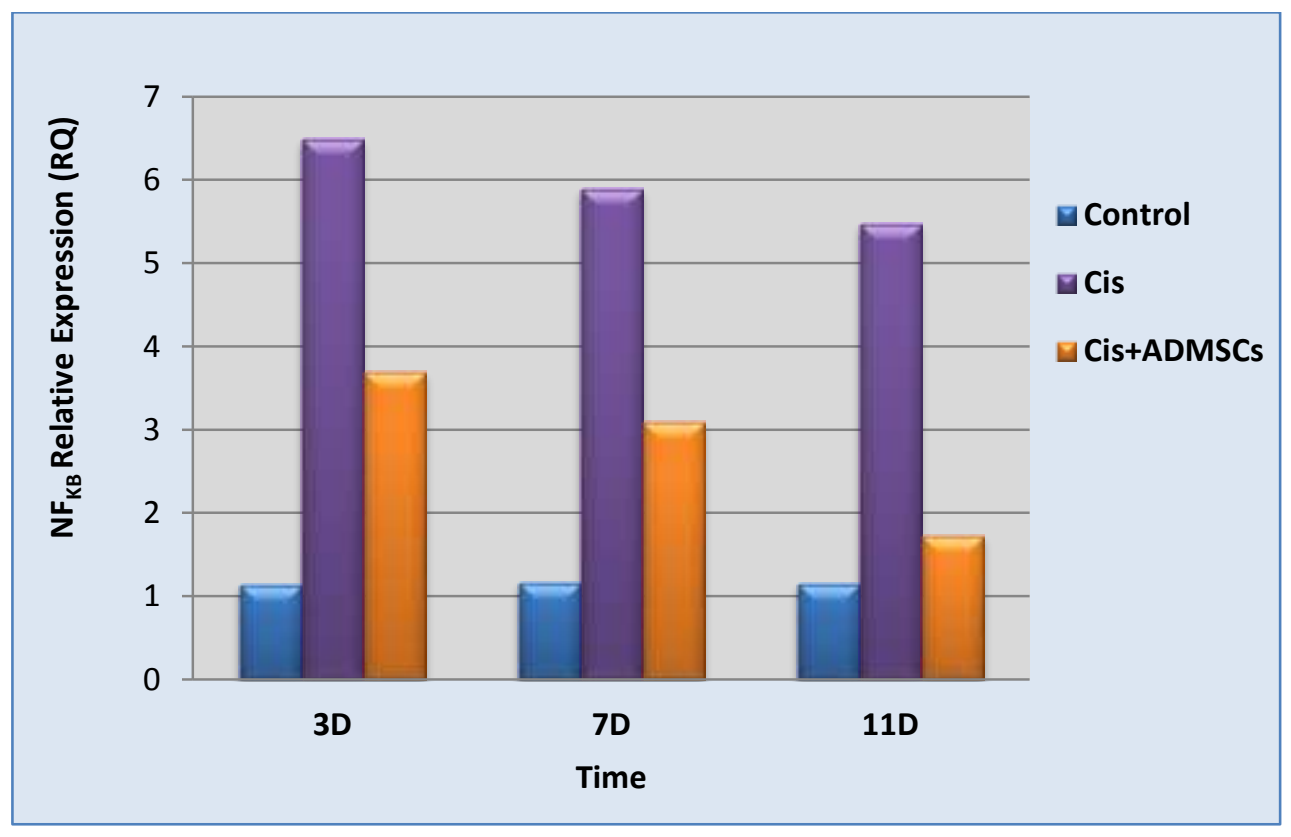

Fig. (5): Effect of ADMSCs on $\mathrm{NF}_{\mathrm{KB}}$ expression in kidney tissue.

\subsection{Effects of ADMSCs on the histopathological changes caused by cisplatin:}

Control group showed normal kidney structure (Figures 6A), on the contrary to control group, cisplatin group showed a significant higher cortical and medullary damage scores at 3, 7 and 11 days (p value <0.05) (Figures 6B-D). Also, cisplatin group showed apoptosis, dilated irregular tubules, loss of brush borders, casts formation and interstitial inflammatory infiltrate. Regarding the stem cells group, it showed statistically significant lower inner cortical and outer medullary degeneration and neutrophil infiltration in comparison to cisplatin group at 3, 7 and 11 days ( $=0.002,0.007$ and 0.002 respectively). Stem cell group showed statistically significant higher cortical and medullary regenerative indices (mitosis, solid tubules and sheets and prominent nucleoli) than control and cisplatin groups ( $\mathrm{p}$ value $<0.05$ ) in cortex and medulla region (Figures 6E, F). 

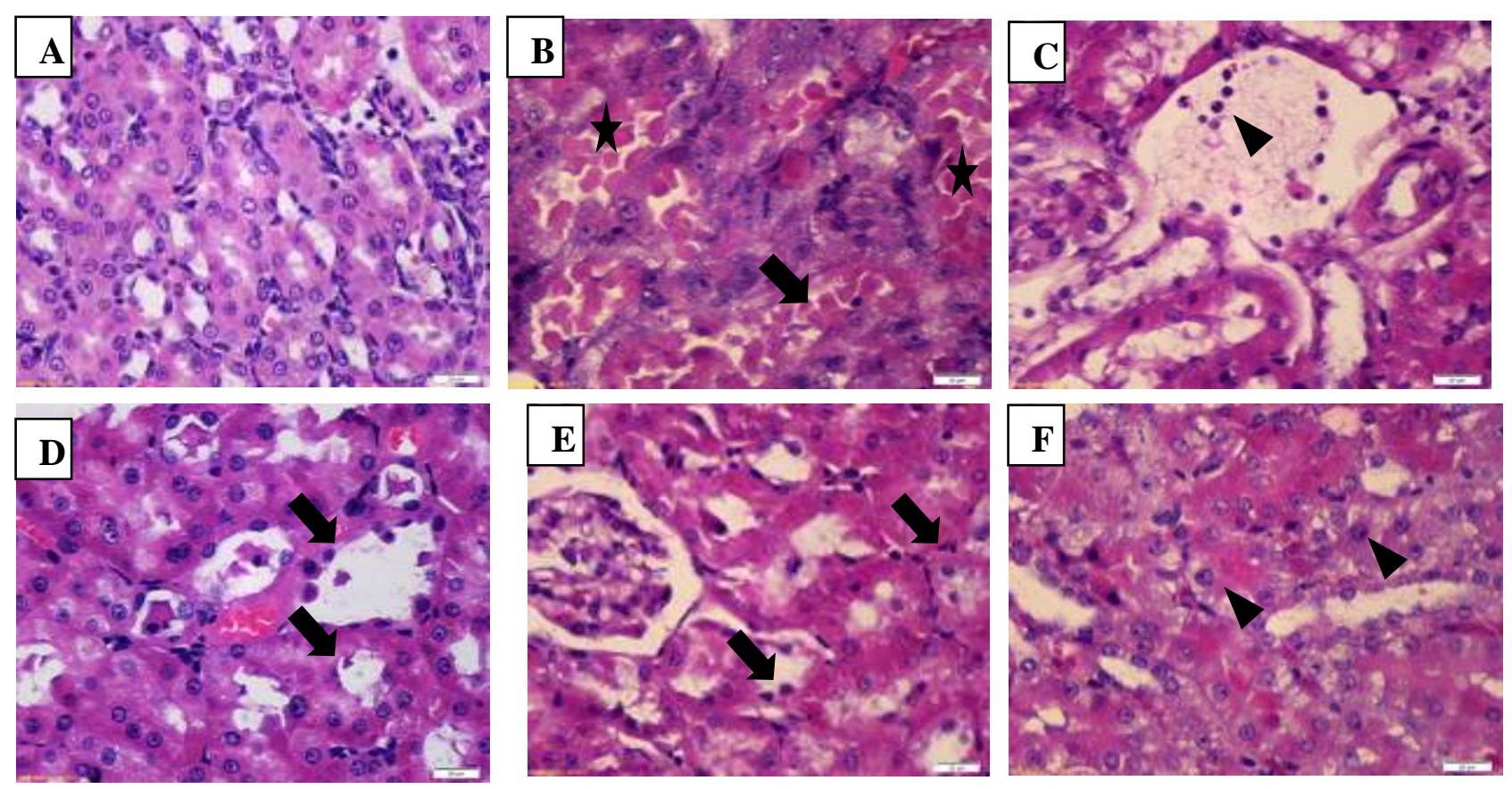

Fig. (6): Photomicrograph of sections through the cortical region showing normal structure. H\&E reduced from X 400. A) Control group. B) Renal degenerative changes in cisplatin group; apoptosis and tubular necrosis (black arrow) in cortex with hyaline casts (star) at 3days. C) Mild interstitial inflammatory infiltrate (arrow head) in cortex at 7 days. D) Mild apoptosis and tubular necrosis (black arrow) in cortex with hyaline casts at 11 days. E) Renal regenerative changes in stem cell treated group showing mitotic figures (black arrow) in cortex at 3 days. F) Prominent nucleoli (arrow head) in cortex at 11 days.

\section{DISCUSSION}

Cisplatin is a chemotherapy, used globally for treating of many solid tumors, but nephrotoxicity that resulted in a significant percentage of patients from its use represents a limiting factor for its clinical usage [14]. Oxidative stress, apoptosis, inflammation and renal histomorphological damage have been reported as several pathogenesis pathways for cisplatin nephrotoxicity [15]. So, the majority of studies for prevention of cisplatin nephrotoxicity have been focused on a therapy that have anti-inflammatory, anti-apoptotic properties and is easy acquisition. ADMSCs were chosen in the present study because of its abundant source, they have more pluripotent stem cells in contrast to bone marrow [16], and they have Multilineage differentiation capability, easy acquisition, and autologous transplantation feasibility [17].

Oxidative stress is the most frequent pathway among the pathways of cisplatin induced acute kidney injury. Cisplatin produce reactive oxygen species (ROS) by disrupting the respiratory chain and cause mitochondrial dysfunction. ROS in renal cells reduce the antioxidant enzyme activity and intracellular concentrations of anti-oxidants by reacting with thiol-containing antioxidant molecules such as glutathione [18].

In the present study, biochemical results showed that cisplatin causes oxidative stress in rat kidneys. MDA was increased as an oxidant agent, and GSH was decreased as antioxidant agents. These results are in agreement with previous studies reported that, cisplatin renal toxicity appeared as increased renal oxidative damage [19], [20].

ADMSCs reno-protective effect involved three possible mechanisms of action, they are, targeting oxidative stress, reduce inflammation and reduce apoptosis [21]. Chin et al. [22] reported that administration 
of ADMSCs could reduce AKI through suppression of the oxidative stress, this possible mechanism was also found in our study, where the administration of ADMSCs partially suppressed oxidative stress and lipid peroxidation by decreasing the level of Malondialdehyde and increasing glutathione reductase in the renal tissue.

As a result of kidney damage, BUN, creatinine and urine protein levels were significantly increased. This may be resulting from direct toxicity caused by reactive oxygen species, that increased in kidney tissue following injection of cisplatin as previously reported [23]. In this study, we found that ADMSCs ameliorated renal dysfunction as demonstrated by decreasing of serum creatinine, BUN and urine protein levels that were in the same line with Elhusseini et al (2016) [24]. Also, the decrease in Malondialdehyde level reflects that ADMSCs could partially suppressed oxidative stress and lipid peroxidation. Concomitantly ADMSCs increased the level of glutathione reductase in the renal tissue until became close to their normal levels at day 11, and that was in accordance to Yao et al. (2015) [25].

Signaling pathway of $\mathrm{NF}_{\mathrm{kB}}$ as well as its expression role for pro-inflammatory genes such as cytokines and chemokines can explain the renal inflammatory mechanism [26], also the above reasons made it a potential target to test any anti-inflammatory agent [27]. Cisplatin can degrade the inhibitory protein $\mathrm{IkB}_{\alpha}$, which facilitates the phosphorylation process of $\mathrm{NF}_{\mathrm{kB}}$ and hence its translocation to the nucleus [28]. In our study, the increase in $\mathrm{NF}_{\mathrm{kB}}$ mRNA gene expression was in agreement with many other studies [29, 30]. In the present study, administration of ADMSCs confirm the second mechanism by inhibiting inflammation as indicated by decreased NFkB mRNA levels in kidney at the three times interval. Consistent with our findings, previous study of Song et al. (2018) found that MSCs could protect kidney from adriamycin-induced nephropathy through anti-inflammatory process mediated by the NF-kB/MAPKs pathway [31].

Previous studies indicated that cisplatin lead principally to apoptosis of renal tubular cells [32]. Hassan et al. (2017) demonstrated that caspase-3 mediated apoptosis has an important role in the execution of apoptotic cell death in case of nephrotoxicity induced by cisplatin [33]. In this study, we demonstrated the third protective mechanism of stem cells, in which ADMSCs could target and attenuate the apoptotic process, which appeared through the decrease in the expression level of caspase- 3 with a significant decrease at day 11 that nearly reachs to normal level, which also are in agreement with another study reported that BMMSCs caused attenuation of caspase-3 in adriamycin-induced nephropathy [34].

Kidney damage, including infiltration of leukocytes, tubules dilation, congestion in blood vessels, necrosis, and degenerative changes in the epithelium of the tubule lumens were shown after cisplatin therapy by microscopic examination. This results was conformable with Elhusseini et al. (2016) findings [24]. Treatment with ADMSCs prior to cisplatin reversed oxidative damage, inflammation and apoptosis in kidneys, consequently it regenerate the kidney and improve its structure and prevented acute kidney injury and histopathological damage starting from day 3, which was compatible with Sakr et al. (2017) [35].

One of our study limitations is the understanding of the mechanism of ADMSCs in improvement of kidney structure after cisplatin therapy. However, their exact mechanisms in repair of the injured kidney might be through trans-differentiation into tubular cells versus through a paracrine process. So our next step will focus on studying the whole mechanism of the homing process of ADMSCs to the injured kidney.

\section{CONCLUSION}

The present study showed that, the renoprotective effect of ADMSCS against cisplatin- induced nephrotoxicity may be explained through their antioxidant effects, anti-inflammatory effects and targeting and attenuating of apoptosis. More future studies may be required to confirm the potential role of ADMSCs in the attenuation of nephrotoxicity. 


\section{CONFLICT OF INTEREST}

The authors have no conflicting financial interest.

\section{REFERENCES}

[1] BELlOMO, R., KELlUM JA., AND RONCO C. Acute kidney injury. The Lancet., 380 (9843), p.756-766, 2012.

[2] BENTLEY, ML., CORWIN, HL., AND DASTA, J. Drug-induced acute kidney injury in the critically ill adult: recognition and prevention strategies. Critical care medicine., 38: p. S169-S174, 2010.

[3] HAYATI F, ET AL. Prevention of cisplatin nephrotoxicity. Journal of nephropharmacology., 5 (1): p. 57, 2016.

[4] ZHAO, J., ZHAO, J., AND JIAO, HJ., Synergistic growth-suppressive effects of quercetin and cisplatin on HepG2 human hepatocellular carcinoma cells. Applied biochemistry and biotechnology., 172 (2): p. 784-791, 2014.

[5] SANCHO-MARTÍNEZ, SM., ET AL. Subcellular targets of cisplatin cytotoxicity: an integrated view. Pharmacology \& therapeutics, 136 (1): p. 35-55, 2012.

[6] TAKAORI, K,. AND YANAGITA, M. Kidney regeneration and stem cells. The Anatomical Record., 297 (1): p. 129-136, 2014.

[7] CAI, C., ET AL. The inhibitory effect of mesenchymal stem cells with rAd-NK4 on liver cancer. Applied biochemistry and biotechnology., 183 (1): p. 444-459, 2017.

[8] SHOKEIR, AA. HARRAZ, AM, AND EL-DIN, ABS. Tissue engineering and stem cells: basic principles and applications in urology. International Journal of Urology., 17 (12): p. 964-973, 2010.

[9] SHEYKHHASAN, M., QOMI, RT., AND GHIASI, M. Fibrin scaffolds designing in order to human adipose-derived mesenchymal stem cells differentiation to chondrocytes in the presence of TGF-ß3. International journal of stem cells., 8 (2): p. 219, 2015.

[10] POURJAFAR, M., ET AL. All-trans retinoic acid preconditioning enhances proliferation, angiogenesis and migration of mesenchymal stem cell in vitro and enhances wound repair in vivo. Cell proliferation., 50 (1): p. e12315, 2017.

[11] SEGHATOLESLAM M, JALALI M, ALAMDARI DH, NIKRAVESH MR, HOSEINI M, FAZEL A, KOLIAKOS G. Optimal incubating time of in vitro bromodeoxyuridine labeling of human umbilical cord blood- mononuclear cells and their functional assessment in ICH rats. J Cell Animal Biology., 6:144-153, 2012.

[12] OHKAWA, H., OHISHI N, AND YAGI K. Assay for lipid peroxides in animal tissues by thiobarbituric acid reaction. Analytical biochemistry., 95(2): p. 351-358, 1979.

[13] BEUTLER, E. Improved method for the determination of blood glutathione. J. lab. clin. Med., 61: p. 882-888, 1963.

[14] SASTRY, J., AND KELLIE, SJ. Severe neurotoxicity, ototoxicity and nephrotoxicity following high-dose cisplatin and amifostine. Pediatric hematology and oncology., 22(5): p. 441-445, 2005.

[15] BARADARAN, A., ET AL. Cisplatin; nephrotoxicity and beyond. Annals of Research in Antioxidants, 1 (2), 2016.

[16] STREM, BM., ET AL. Multipotential differentiation of adipose tissue-derived stem cells. The Keio journal of medicine, 54 (3): p. 132-141, 2005.

[17] ALAJEZ, NM., ET AL. Which stem cells to choose for regenerative medicine application: Bone marrow and adipose tissue stromal stem cells-Similarities and differences. Journal of Nature and Science of Medicine, 1 (2): p. 48, 2018. 
[18] OZKOK, A., AND EDELSTEIN, CL. Pathophysiology of cisplatin-induced acute kidney injury. BioMed research international, 2014, BioMed research international, 2014.

[19] KUHAD, A., ET AL. Effect of curcumin on inflammation and oxidative stress in cisplatin-induced experimental nephrotoxicity. Journal of agricultural and food chemistry, 55 (25): p. 10150-10155, 2007.

[20] KARA, AV., ET AL. Protective Effect of Taxifolin on Cisplatin-Induced Nephrotoxicity in Rats. Analatycal and Quantitative Cytopathology and Histopathology, 41 (2): p. 47-54, 2019.

[21] HUSSEIN, AM., ET AL. Modulation of renal ischemia/reperfusion in rats by a combination of ischemic preconditioning and adipose-derived mesenchymal stem cells (ADMSCs). Canadian journal of physiology and pharmacology, 94 (9): p. 936-946, 2016.

[22] KINNAIRD, T., ET AL. Local delivery of marrow-derived stromal cells augments collateral perfusion through paracrine mechanisms. Circulation, 109 (12): p. 1543-1549, 2004.

[23] ELSHERBINY, NM., ELADL, MA., AND AL-GAYYAR, MM. Renal protective effects of arjunolic acid in a cisplatin-induced nephrotoxicity model. Cytokine, 77: p. 26-34, 2016.

[24] ELHUSSEINI, FM., ET AL. Long term study of protective mechanisms of human adipose derived mesenchymal stem cells on cisplatin induced kidney injury in sprague-dawley rats. Journal of stem cells \& regenerative medicine, 12 (1): p. 36, 2016.

[25] YAO, W., ET AL. Human adipose-derived mesenchymal stem cells repair cisplatin-induced acute kidney injury through antiapoptotic pathways. Experimental and therapeutic medicine, 10 (2): p. 468-476, 2015.

[26] WU, H.T., ET AL. Identifying the regulative role of NF- $\mathrm{kB}$ binding sites within promoter region of human matrix metalloproteinase 9 (mmp-9) by TNF- $\alpha$ induction. Applied biochemistry and biotechnology, 169 (2): p. 438-449, 2013.

[27] RAJU, N., ET AL. Cuscuta chinensis ameliorates immunosuppression and urotoxic effect of cyclophosphamide by regulating cytokines-GM-CSF and TNF-alpha. Applied biochemistry and biotechnology, 176(3): p. 742-757, 2015.

[28] SUNG, M.J., ET AL. Genistein protects the kidney from cisplatin-induced injury. Kidney international, 74 (12): p. 1538-1547, 2008.

[29] BAYOMI, H.S., ET AL. Evaluation of renal protective effects of inhibiting TGF- $\beta$ type I receptor in a cisplatin-induced nephrotoxicity model. European cytokine network, 24 (4): p. 139-147, 2013.

[30] HASSAN, HA., AND EL-GHARIB, NE., Obesity and clinical riskiness relationship: therapeutic management by dietary antioxidant supplementation a review. Applied biochemistry and biotechnology, 176 (3): p. 647-669, 2015.

[31] SONG, IH., ET AL. Mesenchymal stem cells attenuate adriamycin-induced nephropathy by diminishing oxidative stress and inflammation via down regulation of the NF-kB. Nephrology, 23 (5): p. 483-492, 2018.

[32] IWAYAMA, H. AND UEDA, N. Role of mitochondrial Bax, caspases, and MAPKs for ceramideinduced apoptosis in renal proximal tubular cells. Molecular and cellular biochemistry, 379 (1-2): p. 37-42, 2013.

[33] HASSAN, SM., ET AL. Protective effects of apigenin and myricetin against cisplatin-induced nephrotoxicity in mice. Pharmaceutical biology, 55 (1): p. 766-774, 2017.

[34] SARHAN, M., ET AL. Impact of bone-marrow-derived mesenchymal stem cells on adriamycininduced chronic nephropathy. Canadian journal of physiology and pharmacology, 92 (9): p. 733 743, 2014.

[35] SAKR, AE., ET AL. Transplanted adipose derived mesenchymal stem cells attenuate the acute renal injury induced by cisplatin in rats. Egyptian Journal of Histology, 40 (2): p. 169-183, 2017. 